\title{
Urethral Caruncle with Associated Renoureteric Anomalies
}

Sohail Ahmad, *Akash B. Pati, Santosh K. Mahalik, Kanishka Das

ABSTRACT: A urethral caruncle is a rare differential diagnosis for a prolapsed mass at the urethral meatus. The aetiopathogenesis of this entity is unclear. We report a three-year-old female patient who presented to a tertiary care teaching hospital in India in 2019 with intermittent bleeding from the introitus for a month. Investigations revealed a urethral caruncle and associated renal anomalies which has not been described in the previous literature. The patient was discharged with a prescription of a Sitz bath twice daily and advised to apply betamethasone (0.1\%) cream locally once daily. There was a significant improvement after six weeks of therapy; at two-years follow-up, the lesion had disappeared completely.

Keywords: Crossed Fused Ectopia; Case Report; India.

$\mathrm{P}$ EPUBERTAL BLEEDING AT THE INTROITUS is infrequent and raises concerns among parents and health providers alike. A wide variety of differential diagnoses are considered from an innocuous abrasion to malignancy. Urethral aetiologies include mucosal prolapse or polyps. A caruncle is a rare cause that is more common in middle-aged or postmenopausal women. Of 14 cases of urethral caruncle in the paediatric age group described in the English literature, only four have been documented in detail but none have an associated upper urinary tract anomaly. ${ }^{1}$ We describe a patient with a urethral caruncle, bleeding per urethra and associated upper urinary tract anomaly.

\section{Case Report}

A three-year-old female patient presented to a tertiary care teaching hospital in India in 2019 with intermittent bleeding from the introitus for a month. She had a normal perinatal history and there was no history of sexual abuse, genital trauma or recurrent urinary tract infections. In the interim, she was asymptomatic. General physical examination and abdominal examination were unremarkable. The external genitalia were phenotypically female; however, the urethral meatus was circumferentially large and exuberant. The mucosa was relatively more everted along the inferior meatal margin [Figure 1].

The results of routine haematological and biochemical examinations were normal. The urinalysis showed plenty of red blood cells. An ultrasonogram revealed a small left kidney $(45 \times 20 \mathrm{~mm})$, a larger right kidney $(69 \times 28 \mathrm{~mm})$ and crossed fused renal ectopia. Renal cortical scintigraphy (dimercapto succinic acid) showed a left to right crossed fused renal ectopia [Figure 2]. The left renal unit was hydronephrotic and had mildly impaired cortical function and a mid-polar cortical irregularity. The differential function was $43 \%$ in the left renal unit and 57\% in the right renal unit, which was normal. A voiding cystourethrogram was normal.
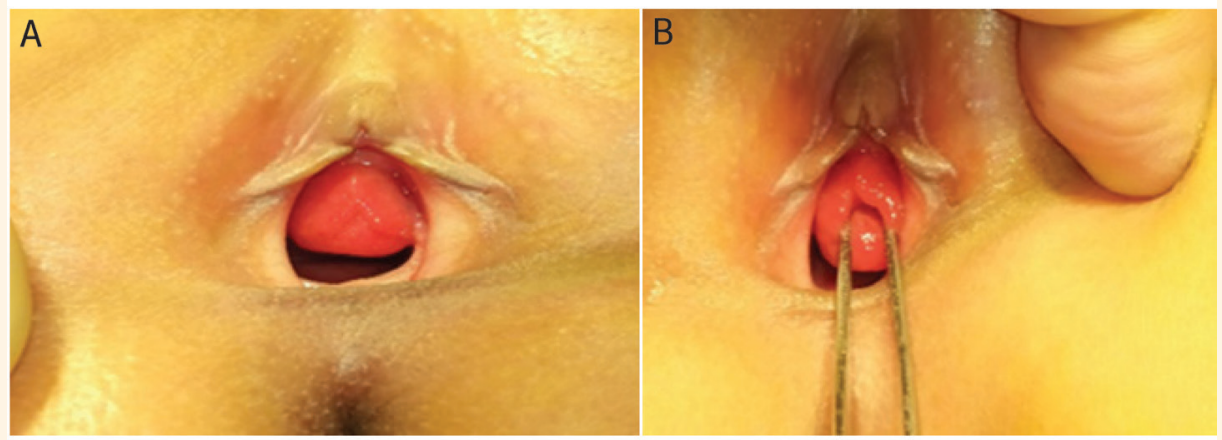

Figure 1: Photographs of the urethra of a three-year-old female patient showing $(\mathbf{A})$ hyperaemic exuberant mucosa at the urethral meatus and $(\mathbf{B})$ a more inferiorly pronounced exuberant mucosa. 


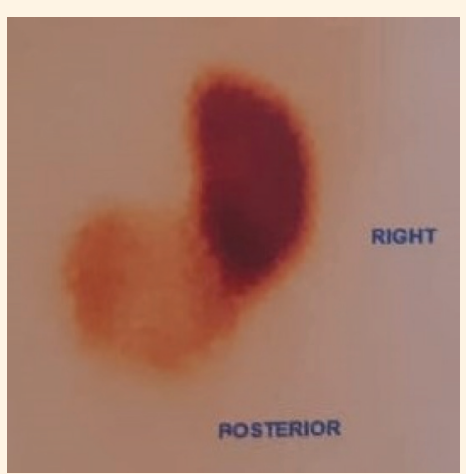

Figure 2: Renal scintigraphy showing left to right crossed fused renal ectopia.

Examination under anaesthesia and cystourethroscopy was performed. The urethral meatus was wide (diameter $=1.8 \mathrm{~cm}$ ) with its edges uniformly protuberant and firm. The mucosa was relatively more everted at the inferior circumference. Cystoscopy revealed abnormal urethra with a mildly trabeculated bladder. The right ureteric orifice was normal, whereas the left was grossly superolateral and patulous. Vaginoscopy was unremarkable.

The patient was discharged on Sitz bath (advised to sit immersed in a warm water bath up to her hip which aids in reducing congestion) twice daily and advised to apply $0.1 \%$ betamethasone cream locally once daily. Following six weeks of therapy, there was a significant reduction in size of the everted mucosa which appeared normal. At two-years follow-up, there was no further gross haematuria and the lesion had disappeared completely. The initial hydronephrosis was non-progressive and renal function was stable on scintigraphy.

Informed consent was obtained from the patient's parents for publication of this case report.

\section{Discussion}

The urethral caruncle is a common benign tumour of the female urethra usually seen in postmenopausal women. An occurrence in the premenarche period, as described in the current case, is rare. The caruncle appears like a raspberry protruding from a quadrant commonly the posterior wall of the urethral circumference. It is rarely observed in other locations. ${ }^{2}$ A circumferential caruncle mimicking a urethral prolapse has been reported only twice since $1964 .{ }^{1}$

The exact aetiology of urethral caruncle is unknown; however, chronic inflammation and oestrogen deficiency have been implicated. ${ }^{1}$ According to Jeffcoate, a true caruncle is a vascular papilloma that arises as a polyp from the posterior lip of the urethra, whereas a pseudo caruncle is a granuloma arising as a diffuse, sessile red lesion. ${ }^{3}$ Urethral caruncles have been reported at birth; hence, a congenital origin is possible. $^{4}$

Symptoms include pain during micturition (51\%), bleeding (49\%), a mass at the meatus (41\%) and an increase in urinary frequency and urgency (36\%). ${ }^{3}$ A 'premature menarche' without other secondary sexual characteristics may indicate a bleeding urethral caruncle. ${ }^{5}$ The current patient had gross intermittent haematuria and a prominent perimeatal mass. The clinical differential diagnosis for a periurethral mass includes urethral prolapse, prolapsing ureterocele and a botryoid bladder or vaginal rhabdomyosarcoma. A urethral prolapse protrudes circumferentially around the meatus like a soft rosette with a central dimple. ${ }^{6}$ Also, both urethral prolapse and polyp are mucosa covered. In contrast, a caruncle is covered with granulation tissue and is liable to bleed. Microscopically, the urethral caruncle is a bed of granulation tissue that may feature squamous or transitional epithelium in places. In addition, marked inflammatory infiltrate and vascular engorgement of the stroma is common.

Most authors consider urethral caruncles as acquired anomalies. ${ }^{1,7}$ The present case features an ectopic left kidney, ectopic termination of the left ureter and a urethral mega meatus. To the best of the authors' knowledge, such anomalies have not been previously reported. It is suggested that patients with urethral caruncle need to be evaluated for associated anomalies in the upper urinary tract. There are no reports available regarding malignancy in a urethral caruncle in children. However, in adults, $2.4 \%$ of all patients with a preoperative diagnosis of urethral caruncle were found to have carcinoma. ${ }^{8}$

Various treatment modalities are advocated ranging from conservative management with Sitz bath, oestrogen creams, topical corticosteroids to surgery. ${ }^{1,5,7}$ In unresponsive cases or those exhibiting a progressive, irregular or suspicious growth, electrocoagulation of the base or excision are surgical options. ${ }^{1}$ Surgical excision may cause urethral stenosis in a circumferential lesion. The present case responded favourably to the initial conservative management.

\section{Conclusion}

The current patient had a granulated mass at the posterior margin of the circumference of the urethral meatus that was diagnosed as a urethral caruncle. She presented with haematuria instead of the typical blood spotting and was successfully conservatively managed. It was associated with a crossed fused renal ectopia and a routine ultrasonographic screening is suggested to detect associated reno-ureteric anomalies. 


\section{AUTHORS' CONTRIBUTION}

All authors were involved in the conceptualisation and preparing of the manuscript. All authors approved the final version.

\section{References}

1 Chiba M, Toki A, Sugiyanma A, Suganuma R, Osawa S, Ishii R, et al. Urethral caruncle in a 9-year-old girl: A case report and review of the literature. J Med Case Re 2015; 9:71. https://doi. org/10.1186/s13256-015-0518-7.

2. Türkeri L, Simşek F, Akdaş A. Urethral caruncle in an unusual location occurring in prepubertal girl. Eur Urol 1989; 16:153-4. https://doi.org/10.1159/000471555.

3. Becker LE. Urethral caruncle: A herald lesion for distal urethral stenosis? J Natl Med Assoc 1975; 67:228-30.
4. Järvi $\mathrm{OH}$, Marin $\mathrm{S}$, de Boer WG. Further studies in intestinal heterotopia in urethral caruncle. Acta Pathol Microbiol Immunol Scand 1984; 92:469-74. https://doi. org/10.1111/j.1699-0463.1984.tb04429.x.

5. Gamage M, Beneragama D. Urethral caruncle presented as premature menarche in a 4-year-old girl. Case Rep Pediatr 2018; 2018:3486032. https://doi.org/10.1155/2018/3486032.

6. Murphy JP, Gatti JM. Abnormalities of the urethra, penis and scrotum. In : Coran AG, Ed. Pediatric Surgery. 7th ed. Philadelphia, USA: Elsevier Saunders, 2012. Pp. 1558

7. Kim KK, Sin DY, Park HW. Urethral caruncle occurring in a young girl: A case report. J Korean Med Sci 1993; 8:160-1. https://doi.org/10.3346/jkms.1993.8.2.160.

8. Marshall FC, Uson AC, Melicow MM. Neoplasms and caruncles of the female urethra. Surg Gynecol Obstet 1960; 110:723-33. 